\title{
Study of Drug Abuse among Trauma Patients in Sohag University Hospitals
}

\author{
Dr.Ahmed M.Abdel Moneim, Dr.Essam M. Abdullah and Mosab M. Rashwan
}

\begin{abstract}
Background: Individuals who actively engage in drug use can become exposed to potentially traumatic events as a result of the consumption and acquisition of drugs as both tend to nurture violent and criminal activity.

Materials and methods: this cross-sectional study conducted on 300 trauma victims of both sexes, admitted to Sohag University hospitals .Urine samples were taken from all patients immediately after admission. Urinary samples were tested by Immunoassay (ABON ${ }^{\mathrm{TM}}$ Multi-Drug) which is one step screen test panel used for qualitative detection of drugs of abuse which includes (Tramadol, Opiate, THC, Amphetamine, Barbiturate, Benzodiazepines).Only positive cases were confirmed by drug analyzer.

Results: Of the 300 patients 82 patients were moderately injured and only two patients were severely injured .Of the 300 patients 46 (15.3\%) tested positive for one or more drugs. The drugs most commonly detected were tramadol (26patients, $8.3 \%$ ), cannabinoids (14patients, 4.6\%), Benzodiazepines (10, 3.3\%) and opium (2 patients, $0.6 \%)$.
\end{abstract}

Conclusions: drug abuse is a common cause of trauma.

\section{Introduction}

Substance abuse is the use of drugs in a manner that is illegal or harmful to oneself and causes significant adverse consequences, such as accidents or injuries, blackouts, legal problems and risky sexual behavior (NIDA; 2005).

Individuals who actively engage in drug use can become exposed to potentially traumatic events as a result of the consumption and acquisition of drugs as both tend to nurture violent and criminal activity. Within both general population and drug using samples findings indicate that the onset of drug use precedes exposure to a traumatic event among males while the onset age for drug use and traumatic event exposure are similar in women (Johnsonet al; 2006).

In 2005 data, the Drug Abuse Warning Network (DAWN) reported that approximately 800,000 visits to participating EDs involved illicit drug use; cocaine use is the most frequent drug mentioned, followed by marijuana, heroin, and stimulants (methamphetamine and amphetamines) (Blow et al ;2011).

An increasingly alarming phenomenon of Tramadol (Tramal) abuse has been heavily demonstrated in the Egyptian community in the period 2007-2010.The alleged usages of tramadol contributed greatly to its popularity and massive use especially among youth and middle-aged groups as a remedy for premature ejaculation and for extended orgasm and to increase sexual pleasure as promoted in many online drug stores and media (Fawzi; 2011).

Trauma is evaluated as the leading cause of deaths and disabilities encountered particularly in the young and productive population, which can contribute to a great burden of socioeconomic problems in developing countries (Pape HC et al; 2000).

\section{Patients and methods}

The present study was a crosssectional study conducted on 300 
trauma victims of both sexes, admitted to Sohag University hospitals. This study included patients aged more than 14 years old attending Sohag University Hospitals. There were no exclusion criteria of medical importance. The protocol was approved by ethical committee in Sohag faculty of medicine.

Immediately after the admission to the ER urine samples were collected from all patients. The samples from the study patients underwent

toxicology screening by an immunoassay (ABONTM Multi-Drug). Urine samples were screened simultaneously for Tramadol, Opiate, THC, Amphetamine, Barbiturates and Benzodiazepines).Recording and documentation of all the obtained data were ensured and well fed into a special sheet designed for the study.The data extracted for the study included demographic data (age, gender, Residence, Occupationand Educational level), trauma data (place of trauma, Cause of trauma,Mode of trauma, Glasgow Coma Score and Severity of trauma).

Statistical AnAlysis:The obtained results were revised, coded and organized for statistical analysis using SPSS (Statistical package for Social Science) version 15 software. Data were presented and suitable analysis was done according to the type of data obtained for each parameter.

\section{Descriptive statistics:}

ÿ Mean, standard deviation ( \pm SD), minimum and maximum values (range) were obtained for numerical data.

$\ddot{y}$ Frequency and percentage were obtained for non-numerical data.

- Analytical statistics:

- Chi-Square test

It was used to examine the relationship between two qualitative variables. The probability $(\mathrm{P})$ was used in all tests. If $\mathrm{P}<0.05$, the comparison was significant.

\section{Results}

Of the 300 patients 289 patients were males and 11 patients were females, 127 patients from urban areas compared to 173 patients from rural areas. The most frequent place of trauma was street by $76 \%$ followed by home $14 \%$ and workplace $10 \%$.The most common cause of trauma was road traffic accidents by $70.3 \%$ followed by interpersonal violence $15.7 \%$ and fall from height $14 \%$.UN intentional trauma was $84.3 \%$ compared to intentional trauma $15.7 \%$.A positive screen was defined as any positive drug result: $46(15.3 \%)$ tested positive for one or more drugs. The drugs most commonly detected were tramadol (26 patients, 8.3\%), cannabinoids (14 patients, $4.6 \%)$, Benzodiazepines $(10,3.3 \%)$ and opium (2 patients, $0.6 \%)$ with out any positive patients for barbiturates and amphetamine. The age range in the patients studied was 14-72 years (mean 30 years). The highest overall incidence of drug use was found in the 14-21 age group (32.6\%) followed by 22-35 age group and 36-50 age group while $>50$ years age group was $15.4 \%$. 


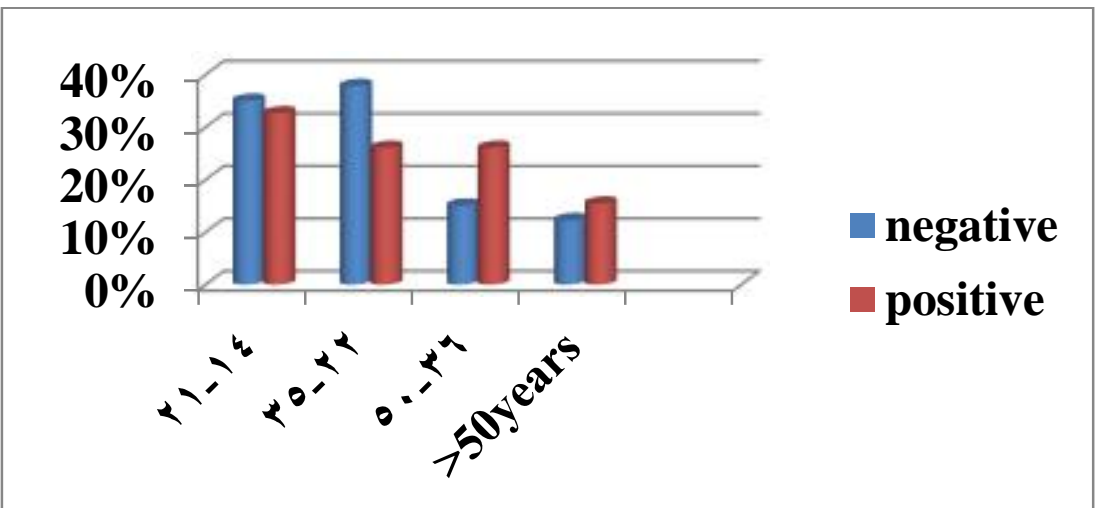

Figure (1): Bar chart showing the distribution of different age groups in relation to screening of drug abuse.

There was no statistical significant difference $(p>0.05)$ between screening of drug abuse as regards age group by using Chi-square test Figure (1). The incidence of drug abuse among intentional trauma was $44.7 \%$ in compared to $9.9 \%$ in UN intentional trauma, There was statistical significant difference $(p<0.05)$ between screening of drug abuse as regards mode of trauma by using Chi-square test.

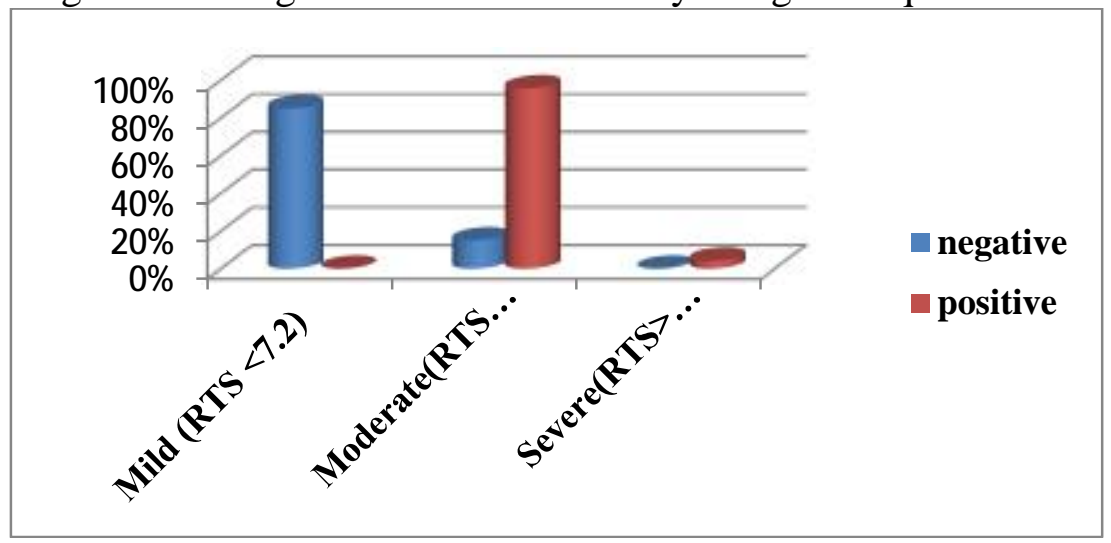

Figure (2): Bar chart showing the distribution of severity of trauma in relation to screening of drug abuse.

Most patients $(n=216)$ were mildly injured; only82 patients were moderately injured while severe trauma only found in 2 patients. There was statistical significant difference $(\mathrm{p}<0.05)$ between screening of drug abuse as regards severity of trauma by using Chi-square test Figure (2).

\section{Discussion}

In this study it was found that the most affected patients whose age between 22-35 years $(36 \%)$ followed by those between 14-21years (34.6\%) which is similar to the study made byFigl et al., (2010) in Australia.Males were preponderance of trauma cases $(96.3 \%$ males compared to $3.7 \%$ females). This is similar to the study done by Walsh et al., (2005) in Maryland. In the current study street comprised the highest frequent place of trauma $(76 \%)$

followed by home which was represented by $(14 \%)$ while the workplace was represented by $(10 \%)$ which is similar the results of a study made by Blondell et al., (2005) in New York where street was represented by $(66 \%)$.In the current study road traffic accidents comprised the highest frequent cause of trauma by about $(70.3 \%)$ followed by interpersonal violence $(15.7 \%)$ and fall from height $(14 \%)$.This is approximately similar to 
the results of a study made by Guardia et al., (2013), in Spain where traffic accidents were represented by (58.9\%).While Bowley et al., (2004) in Johannesburg reported that assault was represented by $(67.6 \%)$ followed by traffic accidents $(20.9 \%)$ which can be explained by that homicide is currently the major cause of death due to injury in South Africa, criminal behaviour in general and violent crimes in particular have been found to be significantly associated with intoxication Bowley et al., (2004).In the current study unintentional trauma comprised the highest frequent mode of trauma by about $(84.3 \%)$ while the intentional trauma was represented by (15.7\%)which go hand in hand with the results recorded by Dischinger et al., (2001) in Maryland. In the current study mild trauma was $(72 \%)$ and moderate trauma was $(27.3 \%)$ while severe trauma was $(0.7 \%)$ which is similar to the results of a study made byDischinger et al. (2001), in Maryland ,USA where mild trauma was(67.3\%).In the current study positive drug abuse was represented by $(15.3 \%)$ and negative drug abuse was represented by $(84.7 \%)$ which is similar to the results of a study made by Penden et al. (2000), in Cape Town.In the current study the most abused drug was tramadol as it was positive in $(8.6 \%)$ of total trauma patients followed by tetrahydrocannabinol (hashish) which was positive in $(4.6 \%)$ of total trauma patients, then benzodiazepines (BZDs) which was positive in $(3.3 \%)$ of total trauma patients while opium was found in $(0.6 \%)$ of total trauma patients finally amphetamine and barbiturates weren't found in any trauma patient which is in contrast to the study conducted by Giovanardi et al. (2005), in Italy the most abused drug was cannabinoids as it was positive in $(16.9 \%)$ of total trauma patients followed by benzodiazepines (BZDs) which was positive in $(10.2 \%)$ of total trauma patients, This can be explained by many of the current forms of violence, rage and increased traffic accidents are closely related to the recently introduced forms of drug abuse, among which tramadol is now becoming the most popular one. In Egypt tramadol prevalence is high due to its wide availability, cheap price and illegal smuggling. (Fawzi, 2011).

\section{Conclusions}

- From this study 14-21 years old and 22-35 years old are the risky age groups affected by trauma due to drug use and males are more predominant than females.

- Trauma occurs more frequently at rural areas.

- Manual workers were the most affected occupation.

- Street was the most common place of trauma.

- Road traffic accidents were the most common cause of injury.

- Un intentional injury was the most common mode of trauma.

- Most patients had mild trauma.

- Tramadol was the commonest drug of abuse followed by THC.

\section{References}

1. Blondell R.D., Dodds H.N., Looney S.W., Lewis C.M., Hagan J.L., Lukan J.K and Servoss T.J.(2005):Toxicology screening results: injury associations among hospitalized trauma patients. Journal of Trauma and Acute Care Surgery, 58(3):561-570.

2. Blow F.C., Walton M.A., Barry K.L., Murray R.L., Cunningham R.M., Massey L.S., Chermack S.T andBooth B.M. (2011): Alcohol and drug use among patients presenting to an inner-city emergency Department, Addictive Behaviors, 36:793-800.

3. Bowley D.M., Rein P., Snyman T., Boffard K.D., Cherry R. and Vellema, J.( 2004): Substance abuse 
and major trauma in Johannesburg. South African Journal of Surgery, 42(1):7-10.

\section{DischingerP.C., MitchellK.A.,} KuferaJ.A., SoderstromC.A. and Lowenfels A.B. (2001): A longitudinal study of former trauma center patients: the association between toxicology status and subsequent injury mortality. Journal of Trauma and Acute Care Surgery, 51(5):877-886.

5. Fawzi M. M. (2011): Some medico legal aspects concerning tramadol abuse: The new Middle East youth plague 2010. An Egyptian overview. Egyptian journal of Forensic Sciences, 1(2): 99-102.

6. Giovanardi D., Castellana C.N., Pisa S., Poppi B., Pinetti D., Bertolini A and Ferrari A.(2005): Prevalence of abuse of alcohol and other drugs among injured drivers presenting to the emergency department of the University Hospital of Modena, Italy. Drug and Alcohol Dependence, 80(1):135-138.

7. Guardia S.C., Rodríguez-Bolaños S., López F.G., Lara-Rosales R., Sánchez F.P., Rayo A. and Fernandez-Mondejar E.( 2013): Alcohol and/or drug abuse favors trauma recurrence and reduces the trauma-free period. Medicina Intensiva (English Edition), 37(1):6-11.

8. Johnson S.D., Striley S and Cottler L.B. (2006): The association of substance use disorders with trauma exposure and PTSD among African American drug users, Addictive Behaviors, 31, 2063-2073

9. National Institute on Drug Abuse (NIDA) (n.d.) (2005): Understanding Drug Abuse and trauma http://www.nida.nih.gov/Infofacts/unde rstand.html/ Accessed 30/8/2015.

10.Pape H.C., Oestern H.J., Leenen L., Yates D.W., Stalp M., Grimme K., Tscherne H., Krettek C., and the German Polytrauma Study Group (2000): Documentation of blunt trauma in Europe, Eur. J. Trauma; 5, 233-247.

11.Peden M., Van der Spuy J., Smith P and Bautz P. (2000): Substance abuse and trauma in Cape Town. South African Medical Journal, 90(3): 251255.

12. Walsh J.M., Flegel R., Atkins R., Cangianelli L.A., Cooper C., Welsh $\mathrm{C}$ and Kerns T.J.(2005): Drug and alcohol use among drivers admitted to a Level-1 trauma center. Accident Analysis and Prevention, 37(5):894901. 
SOHAG MEDICAL JOURNAL

Vol. 21 No.2 July 2017 